AperTO - Archivio Istituzionale Open Access dell'Università di Torino

Developing Age and Gender Adjusted Normative Reference Values for the Difficulties in Emotion Regulation Scale (DERS)

This is a pre print version of the following article:

Original Citation:

Availability:

This version is available http://hdl.handle.net/2318/1647990

since 2017-09-19T15:05:54Z

Published version:

DOI:10.1007/s10862-017-9611-0

Terms of use:

Open Access

Anyone can freely access the full text of works made available as "Open Access". Works made available under a Creative Commons license can be used according to the terms and conditions of said license. Use of all other works requires consent of the right holder (author or publisher) if not exempted from copyright protection by the applicable law. 
This is the author's final version of the contribution published as:

Giromini, Luciano; Ales, Francesca; de Campora, Gaia; Zennaro, Alessandro; Pignolo, Claudia. Developing Age and Gender Adjusted Normative Reference Values for the Difficulties in Emotion Regulation Scale (DERS). JOURNAL OF PSYCHOPATHOLOGY AND BEHAVIORAL ASSESSMENT. None pp: 1-10.

DOI: $10.1007 / \mathrm{s} 10862-017-9611-0$

The publisher's version is available at: http://link.springer.com/10.1007/s10862-017-9611-0

When citing, please refer to the published version.

Link to this full text:

http://hdl.handle.net/ 


\section{Journal of Psychopathology and Behavioral Assessment Developing Age and Gender Adjusted Normative Reference Values for the Difficulties in Emotion Regulation Scale (DERS) \\ --Manuscript Draft--}

\begin{tabular}{|c|c|}
\hline Manuscript Number: & JOBA-D-16-00239 \\
\hline Keywords: & Emotion regulation; DERS; age; gender; reference values. \\
\hline \multicolumn{2}{|c|}{$\begin{array}{l}\text { Corresponding Author Secondary } \\
\text { Information: }\end{array}$} \\
\hline \multicolumn{2}{|c|}{ Corresponding Author's Institution: } \\
\hline \multicolumn{2}{|c|}{ First Author Secondary Information: } \\
\hline \multirow[t]{5}{*}{ Order of Authors: } & Luciano Giromini \\
\hline & Francesca Ales \\
\hline & Gaia de Campora \\
\hline & Alessandro Zennaro \\
\hline & Claudia Pignolo \\
\hline \multicolumn{2}{|c|}{ Order of Authors Secondary Information: } \\
\hline
\end{tabular}


Developing Reference Values for the DERS

RUNNING HEAD: Developing Reference Values for the DERS

\title{
Developing Age and Gender Adjusted Normative Reference Values for the Difficulties in Emotion Regulation Scale (DERS)
}

\author{
Luciano Giromini $^{1}$, Francesca Ales ${ }^{1}$, Gaia de Campora ${ }^{2}$, \\ Alessandro Zennaro ${ }^{1}$, \& Claudia Pignolo ${ }^{1}$ \\ ${ }^{1}$ Department of Psychology, University of Turin - Italy \\ ${ }^{2}$ Department of Dynamic and Clinical Psychology, Sapienza University of Rome - Italy
}

Corresponding Author:

Luciano Giromini, Ph.D., Department of Psychology, University of Turin, Italy. Tel. (+39) 011

670 3060; email: luciano.giromini@unito.it

Co-authors' email addresses:

Francesca Ales: francesca.ales@ outlook.it

Gaia de Campora: gaiadecampora@gmail.com

Alessandro Zennaro: alessandro.zennaro@unito.it

Claudia Pignolo: claudia.pignolo@unito.it 
Developing Reference Values for the DERS

\begin{abstract}
Emotion Regulation (ER) is an important aspect of every-day behavior relevant to both clinical and diagnostic practice. To date several studies have investigated the psychometric properties of Difficulties in Emotion Regulation Scale (DERS; Gratz \& Roemer, 2004) scores, however, the extent to which the DERS is affected by the gender and/or age of the respondents has so far been only poorly investigated. Furthermore, no studies have yet offered suggestions or guidelines on how to interpret different DERS scores. To fill this gap, the current study aimed at: (a) investigating with two relatively large Italian samples the influence of gender and age on DERS scores; (b) introducing a new approach to develop age and gender adjusted normative reference values for the DERS; (c) providing suggestions on how to interpret the resultant, age and gender adjusted, T-transformed, DERS scores. The results of our analyses show that within our first Italian sample $(n=808)$, DERS scores tended to decrease with age, whereas gender had a small impact on them. Moreover, and more importantly, our age and gender adjusted, T-transformed, DERS scores calculated based on this first sample almost perfectly matched the scores produced by a second, independent, nonclinical Italian sample $(n=404)$. Our findings thus support the effectiveness of our method to generate normative reference values for the DERS. Keywords: Emotion regulation; DERS; age; gender; reference values.
\end{abstract}


Developing Reference Values for the DERS

\title{
Developing Age and Gender Adjusted Normative Reference Values for the Difficulties in Emotion Regulation Scale (DERS)
}

\begin{abstract}
Every day, we are exposed to a wide variety of potentially arousing stimuli, and inappropriate, extreme or unchecked emotional reactions to those stimuli could impede our functional fit within society. As such, we must engage in some form of Emotion Regulation (ER) almost all of the time (Koole, 2009).
\end{abstract}

According to Cole, Michel, and Teti (1994), ER may be defined the ability to respond to the continuous demands of experience with the range of emotions in a manner that is socially acceptable and sufficiently flexible to allow spontaneous reactions as well as the ability to delay spontaneous reactions as needed. Along the same lines, Thompson (1994) conceptualized ER as the extrinsic and intrinsic processes responsible for the monitoring, evaluating, and modifying emotional reactions. More broadly, ER may be defined as the assortment of those complex psychological processes that, in a given situation, control the initiation, inhibition or modulation of states or behaviors such as subjective experiences (feelings), cognitive responses (thoughts), emotion-related physiological responses (heart rate or hormonal activity), and emotion-related behaviors (bodily actions or expressions) (Gross, 1998). Functionally, ER also refers to processes such as the tendency to focus on the task and the ability to repress inappropriate behaviors under instruction.

The ability to regulate emotions is relevant to both clinical and diagnostic practice. From an assessment standpoint, different ER strategies are typical of different clinical conditions. For example, avoidance of social situations is typical of both social anxiety disorder (Wells \& Papageorgiou, 1998) and avoidant personality disorder (Campbell-Sills \& Barlow, 2007), while 
Developing Reference Values for the DERS

rumination is typical of major depression (Nolen-Hoeksema, Wisco, \& Lyubomirsky, 2008). From a more clinically oriented standpoint, deficits in ER are found in several pathological conditions. For example, recent research has demonstrated that ER is important to depression (Gross \& Muñoz, 1995), generalized anxiety disorder (McLaughlin, Mennin, \& Farach, 2007; Mennin, Heimberg, Turk, \& Fresco, 2005), alcoholism and substance abuse (Fox, Axelrod, Paliwal, Sleeper, \& Sinha, 2007; Fox, Hong, \& Sinha, 2008; Gratz, Bornovalova, Delany-Brumsey, Nick, \& Lejuez, 2007), self-injury (Klonsky, 2009), suicide (Zlotnick, Donaldson, Spirito, \& Pearlstein, 1997), eating disorders (de Campora, Giromini, Larciprete, Li Volsi, \& Zavattini, 2014; de Campora, Larciprete, Delogu, Meldolesi, \& Giromini, 2015; Sim \& Zeman, 2005, 2006; Whiteside et al., 2006), borderline personality disorder (Glenn \& Klonsky, 2009; Linehan, 1993), and posttraumatic stress (Tull, Barrett, McMillan, \& Roemer, 2007).

Currently, one of the most widely adopted instruments to measure deficits in ER is the Difficulties in Emotion Regulation Scale (DERS), which was originally introduced by Gratz and Roemer in 2004. The DERS is a 36-item, self-report questionnaire assessing multiple aspects of emotion dysregulation. It yields a total score as well as scores on six scales derived through factor analysis: (1) Non-acceptance of emotional responses (Nonacceptance), (2) Difficulties engaging in goal directed behavior (Goals), (3) Impulse control difficulties (Impulse), (4) Lack of emotional awareness (Awareness), (5) Limited access to emotion regulation strategies (Strategies), (6) Lack of emotional clarity (Clarity).

The validity and reliability of DERS scores have been investigated in several, empirical studies from all over the world. In particular, an Italian (Giromini, Velotti, de Campora, Bonalume, \& Zavattini, 2012), Turkish (Rugancı \& Gençöz, 2010), Spanish (Hervás \& Jódar, 2008), Korean (Cho \& Hong, 2013), Greek (Mitsopoulou, Kafetsios, Karademas, Papastefanakis, \& Simos, 
Developing Reference Values for the DERS

2013), French (Dan-Glauser \& Scherer, 2015), Brazilian Portuguese (Miguel, Giromini, Colombarolli, Zuanazzi, \& Zennaro, 2016), and European Portuguese (Coutinho, Ribeiro, Ferreirinha, \& Dias, 2010) versions have recently been developed and validated. The results of all this study strongly support the cross cultural adaptability and applicability of the instrument.

\section{Impact of Gender and Age on DERS}

While the DERS has been largely investigated internationally, to date very few studies have inspected whether DERS scores associate with the gender and/or age of the respondents. Below we briefly review the relevant literature on this topic.

As for the relationship of DERS scores to gender, the original, DERS development study by Gratz and Roemer (2004) reported no gender differences for the total and for five of the six subscale, DERS scores - the only significant difference was that men scored higher than women on Awareness. The exact same pattern of findings was observed also in the Greek validation study, where men and women differed on Awareness only, and produced comparable scores on all other dimensions (Mitsopoulou et al., 2013). Within the Brazilian sample (Miguel et al., 2016), women scored slightly higher than men on Nonacceptance and Impulse, but no other significant gender differences emerged. The Italian (Giromini et al., 2012), Spanish (Hervás \& Jódar, 2008), and Turkish (Rugancı \& Gençöz, 2010) validation studies of the DERS did not detect any significant gender differences, for any of the DERS scores. Conversely, using a sample of Turkish adolescents, Sarıtaş-Atalar, Gençöz e Özen (2013) recently found that women scored higher than men did on Goals, whereas men scored higher than women did on Awareness; however, no other significant gender differences were observed for any of the other dimensions. Taken together, thus, the available literature seems to indicate that gender has a small or no impact on DERS scores. 
Developing Reference Values for the DERS

As for the relationship between DERS and age, it is commonly accepted that ER skills improve with the passing of years and some DERS studies seem to confirm this trend. For example, Orgeta (2009) reported that compared to older adults, younger adults produced significantly higher DERS scores on all dimensions, except for Awareness and Nonacceptance. Likewise, Miguel et al. (2016) observed significant or marginally significant correlations with age in the same, expected direction, for all DERS scales, with effect sizes ranging from $r=-.07$ to $r=-.25$. Overall, however, more research on this topic is needed, prior to concluding that DERS scores do decrease with age.

\section{The Current Study}

To date several studies have investigated the psychometric properties of DERS scores with multiple, international samples. However, the extent to which the DERS is affected by the gender and/or age of the respondents has so far been only poorly investigated. Perhaps more importantly, no studies have yet offered suggestions or guidelines on how to interpret different DERS scores. As such, researchers or practitioners willing to use and interpret DERS scores currently do not have any specific benchmarks or cut-off scores to rely on.

The current study aimed at contributing to this literature by: (a) investigating with a relatively large Italian dataset the influence of gender and age on DERS scores; (b) introducing a new approach to develop age and gender adjusted normative reference values for the DERS; (c) providing suggestions on how to interpret the resultant, age and gender adjusted, T-transformed, DERS scores. Although in this article we apply our method to an Italian sample only, we anticipate that the approach we introduce here may serve as reference point for other, non-Italian authors willing to develop age and gender adjusted DERS normative reference values for use within their countries. 


\section{Developing Reference Values for the DERS}

\section{Materials and Methods}

This study used archival data, retrieved from three previously published research articles. In the first of these articles, Giovannini et al. (2014) reported on the reliability and validity of scores from an Italian version of Five Facet Mindfulness Questionnaire (FFMQ; Baer, Smith, Hopkins, Krietemeyer, \& Toney, 2006), a 39-item measure of mindfulness. In the second, Giromini, Brusadelli, Di Noto, Grasso, Lang (2015) evaluated the validity and reliability of scores from the Balanced Index of Psychological Mindedness (BIPM; Nyklíček \& Denollet, 2009), a brief measure of psychological mindedness. Finally, the third article (Giromini, et al., 2015) provided data on the cross-cultural adaptability of the Interpersonal Competence Questionnaire (ICQ; Buhrmester, Furman, Wittenberg, \& Reis, 1988), a 40-item self-report measuring five domains of interpersonal competence. In all these studies, the Italian version of the DERS (Giromini et al., 2012) was administered as a measure of convergent validity for the scores of the instruments under investigation (i.e., the FMMQ, BIPM, and ICQ).

\section{Participants}

The initial sample included data from 1,344 adults, ranging in age from 18 to 64 years. About $70 \%$ were women, the majority were students (i.e., about 80\%), and all were Italian citizens. Consistent with previous studies on the DERS (e.g., Giromini et al., 2012; Gratz \& Roemer, 2004), we next removed from the analyses records with missing data on one or more item of the DERS. At this step, the sample was reduced to 1,228 adults. Finally, because we wanted to investigate the impact of age and gender on DERS scores, all data with missing information on either age, gender, or both these variables were removed, too. The final sample was thus reduced to 1,212 adults. A demographic characterization of this sample is detailed in Table 1.

\section{Procedure}




\section{Developing Reference Values for the DERS}

Participants were student and non-student, adult volunteers. Students were recruited at two Italian universities, i.e., University of Milano - Bicocca and Sapienza University of Rome. Nonstudent participants were collected via snowball sampling by Giovannini et al. (2014), with the purpose to extend the age range of their initial, student sample. In all cases, prior to beginning data collection, participants were informed that they would have to fill out a number of questionnaires anonymously and that they could withdraw their consent at any time. All signed an informed consent form prior to being administered the questionnaires. Inclusion criteria were: being Italian citizen, being fluent in Italian, and not receiving psychiatric therapy or psychiatric medications.

\section{Measures}

Each of the studies from which our data were retrieved administered the DERS along with a number of other measures. For the purposes of the current study, however, only DERS data were analyzed. As indicated above, the DERS is a widely investigated, self-report instrument measuring difficulties in ER. The validity and reliability of its scores have been demonstrated worldwide. Important to our goal, the scores of the Italian DERS version have demonstrated excellent psychometric properties, too (e.g., de Campora et al., 2014; Giovannini et al. 2014; Giromini et al., 2012; Giromini, de Campora, et al., 2015).

As noted above, the current study used data retrieved from Giovannini et al. (2014), Giromini, Brusadelli, et al. (2015), and Giromini, de Campora et al. (2015). In these studies, internal consistency was adequate to excellent, with alpha values ranging from .77 to .92 in the first study, from .74 to .93 in the second study, and from .72 to .95 in the third study. Internal consistency values obtained in the present study - i.e., after combining all available data from the three samples - are reported in Table 2.

\section{Data Analysis}




\section{Developing Reference Values for the DERS}

In addition to testing the influence of age and gender on its scores, the main purpose of this article was to develop and cross-validate age and gender adjusted normative reference values for the DERS. To do so, we split our initial, combined dataset $(N=1,212)$ into two, randomly generated, subsamples. More specifically, two thirds of the data, i.e., our "developmental sample" $(n=808)$, was used to develop the formulas to generate our age and gender adjusted, normative DERS scores. The remaining data, i.e., our "validation sample" ( $n=404)$, was next used to investigate the extent to which an independent, nonclinical sample would resemble our newly generated, DERS reference values.

To generate our age and gender adjusted normative reference values, we first used the developmental sample, and tested a series of multiple regression models. For each DERS scale, age and gender (dummy code, with $\mathrm{M}=0$ and $\mathrm{F}=1$ ) were entered as predictors, and the target DERS score was used as criterion. The prediction equations derived from the resultant, raw $b$ weight values were then used to estimate the expected DERS scores of each participant based on his/her age and gender. The differences between these estimates and the observed DERS values were finally added to the mean DERS scores of our sample, so as to produce age and gender adjusted DERS scores. These scores basically reflect what the DERS of a given person would look like if his/her gender (dummy code) and age were held constant at the mean values found in our developmental sample. A similar statistical procedure has been used before in the literature, for example to produce self-report scores adjusted for social desirability (e.g., Blumberg, Giromini, \& Jacobson, 2016) or Rorschach inkblot method scores adjusted for engagement and cognitive sophistication or complexity (Meyer, Viglione, Mihura, Erard, Erdberg, 2011). Lastly, for each of these scores, we produced descriptive statistics to generate the formulas converting these raw, age and gender adjusted DERS values into T scores. 
Developing Reference Values for the DERS

To evaluate the representativeness and applicability of these newly developed, age and gender adjusted, T-transformed, DERS scores, we next inspected our validation sample. More in detail, we used Bayesian statistics and determined the degree of fit between our proposed norms and the DERS values produced by our validation sample. Moreover, to confirm that these adjusted DERS scores are not affected by the age and gender of the respondents, we ran additional, correlation-based, statistical analyses.

\section{Results}

\section{Development of Age and Gender Adjusted DERS Scores}

Within the developmental sample $(n=808)$, a series of multiple regressions was performed to obtain the formulas to generate age and gender adjusted DERS scores. As reported in Table 3, all models were statistically significant, $F(2,805) \geq 5.55, p \leq .004$, explaining $1 \%$ to $5 \%$ of the variance of the DERS scores. In all cases age produced statistically significant beta weights, $p \leq$ .008 , whereas gender did not significantly contributed to any of the models, $p \geq .086$. The association of age to DERS was in the expected direction for all scales, i.e., the higher the age, the lower the DERS score, except for Awareness, for which older individuals tended to produce higher scores.

The resultant parameters from these multiple regression equations were then used to develop our age and gender adjusted DERS scores. More specifically, the intercepts and regression coefficients reported in Table 3 were used to estimate the expected DERS scores of each participant based on his/her age and gender. For example, for Nonacceptance, the expected subscale score based on age and gender was given by the following equation: 
Developing Reference Values for the DERS

$$
=14.528-(\text { Age } \times .060)-(\text { Gender } \times .100)
$$

where age is measured in years, and gender is coded as dummy variable, with $\mathrm{M}=0$ and $\mathrm{F}$ $=1$. Next, the residuals between these estimates and the observed DERS scores were added to the mean DERS scores, thus producing our raw, age and gender adjusted DERS scores. For instance, the age and gender adjusted score for Nonacceptance was calculated as follow:

Age \& Gender Adj. Nonacceptance Score $=$

$$
=((14.528-(\text { Age } \times .060)-(\text { Gender } \times .100))-\text { Raw Value })+12.850
$$

where raw value refers to the raw Nonacceptance score, and 12.850 is the mean Nonacceptance value found in our developmental sample. Finally, these raw scores were converted into T scores based on the mean and standard deviation values found in our developmental sample, and reported in Table 4.

All final equations to produce our age and gender adjusted, DERS T-scores are presented in Appendix A. When looking at these formulas, the reader should keep in mind that within the developmental sample, the mean values of the adjusted and non-adjusted scores are virtually identical. Indeed, our procedures to control for age and gender basically correct the DERS scores so as to mimic what one would observe if those scores were produced by individuals with the same age and gender of our developmental sample. As such, the same mean values of the DERS scores were initially summed to the residuals between the estimated and observed DERS values, and then they were subtracted so as to produce the T scores. For this reason, they are not included in the formulas reported in Appendix A. 
Developing Reference Values for the DERS

\section{Representativeness of DERS Age and Gender Adjusted T-Scores}

To test the representativeness and applicability of our age and gender adjusted, DERS Tscores, we next inspected our validation sample. The main goal was to evaluate whether the scores produced by an independent, nonclinical sample comprised of 404 adults would resemble those of our newly developed, normative reference values. Thus, we intended to test the null hypothesis (H0) that the average age and gender adjusted DERS T-score produced by our validation sample would not be statistically different from the mean value of $T=50$. Because classic null hypothesis significance testing (NHST) does not allow to provide evidence in support to H0 (Altman \& Bland, 1995), we implemented Bayesian statistics.

Bayesian statistics are still under-utilized in assessment literature (albeit see Giromini, Viglione, \& McCullaugh, 2014; Reese, Viglione \& Giromini, 2014). However, they provide an excellent framework to testing $\mathrm{H} 0$, as they essentially compare the evidence supporting $\mathrm{H} 0$ against the evidence proving it wrong (for background, see Rouder \& Morey, 2011 or Wagenmakers, 2007). In particular, when evaluating t-test statistics, Rouder, Speckman, Sun, Morey, and Iverson's (2009) JZS Bayes Factor (Equation 1) is an optimal solution to calculate the relative posterior probability of $\mathrm{H} 0$ versus alternative hypotheses, given the data. The JZS Bayes Factor odds ratio is then typically interpreted using Jeffreys' (1961) criteria, i.e., values greater than 3 reveal "some evidence" for $\mathrm{H} 0$, values greater than 10 reveal "strong evidence" for $\mathrm{H} 0$, and values greater than 30 reveal "very strong evidence" for H0. Vice versa, JZS Bayes Factor values lower than $.33, .10$, and .03 indicate, respectively, "some evidence," "strong evidence," and "very strong evidence" against $\mathrm{H} 0$.

Table 5 shows descriptive statistics for the age and gender adjusted DERS T-scores calculated within our validation sample $(n=404)$, along with the respective one-sample t-tests and 
Developing Reference Values for the DERS

JZS Bayes Factor (or JZS B) values testing the null hypothesis that the average T values are equal to 50. According to Jeffreys' (1961) characterization of Bayes Factor values, our data provide strong to very strong support for H0, thus suggesting that our validation sample produced DERS scores that very closely resembled our age and gender adjusted normative reference values.

Lastly, to confirm that these age and gender adjusted DERS T-scores are not affected by the age and gender of the respondents, we ran additional correlation and point bi-serial correlation analyses. The results of these additional analyses are reported in Table 6. None of the age and gender adjusted DERS T-scores produced significant correlations. Also noteworthy, none reached absolute correlation values of .10. Conversely, the non-adjusted, raw DERS scores negatively correlated with age and produced one significant point bi-serial correlation with gender.

\section{Discussion and Conclusions}

The current study aimed at testing the influence of gender and age on Difficulties in Emotion Regulation Scale (DERS; Gratz \& Roemer, 2004) scores, and at introducing a novel approach to develop age and gender adjusted normative reference values for the DERS. We used archival, Italian data, and split our relatively large dataset $(N=1,212)$ into two groups: two thirds of the data were used to test the association of gender and age to DERS scores while generating normative reference values; the remaining data were used to test the representativeness and applicability of these newly developed, age and gender adjusted, T-transformed, DERS scores. Taken together, our findings show that: (a) whereas DERS scores tended to decrease with age, gender had a small impact on them; (b) our age and gender adjusted normative reference values for the DERS almost perfectly matched the scores produced by an independent, nonclinical sample comprised of 404 adults. As such, we believe that our method to generate normative reference 
Developing Reference Values for the DERS

values performed very well, and that it may be adopted in the future in various other cultural contexts to produce valid, reliable, and representative norms for the DERS.

The fact that in our sample the DERS scores were influenced by the age of the respondents is not too surprising. Both Orgeta (2009) and Miguel et al. (2016) found a similar result in previous studies conducted with the DERS. Furthermore, as noted by Urry and Gross (2010), while aging associates with losses in various physical and cognitive domains, older adults typically report higher well-being than younger individuals and this phenomenon is likely accounted for by the fact ER skills improve with age. Accordingly, to accurately assess one's ER skills and difficulties, DERS scores need to be corrected for age, or else younger individuals' difficulties would tend to be overestimated, whereas older individuals' problems would tend to be underestimated.

Conversely, in our sample gender had a small or negligible influence on DERS scores. This finding is overall in line with previous DERS literature (Giromini et al., 2012; Hervás \& Jódar, 2008; Ruganc1 \& Gençöz, 2010), albeit some studies did report statistically significant gender differences for one of the DERS scales, i.e., Awareness (Gratz \& Roemer, 2004; Mitsopoulou et al., 2013). In our opinion, because the available studies on the association of gender to DERS scores have so far produced only mixed or controversial results, it is important at this stage of knowledge to retain gender in the equation formulas leading up to the adjusted, normative reference scores for the DERS. In line with this position, examination of Table 6 reveals that one of the raw DERS scores significantly associated with gender (albeit with a small effect size), whereas none of the adjusted, $\mathrm{T}$ scores produced statistically significant associations.

Despite $\mathrm{T}$ scores are commonly used in clinical practice to interpret how scores diverge from the mean of a normative sample, DERS T scores were never developed before. Given that T score distribution has a mean of 50 and a standard deviation of $10, \mathrm{~T}$ scores can be easily 
Developing Reference Values for the DERS

interpreted and can quickly reveal how far a person's score diverges from the mean of the normative sample. For example, a raw score of 20 on the Nonacceptance scale may indicate that the person obtained a score higher than the mean of the normative sample $(M=12.85, S D=4.76)$. However, to know how much that score is divergent from the mean, one should compute the $z$ score (or utilize a similar procedure) to finally know that that person's score is 1.5 standard deviation higher than the mean of the normative sample. This procedure would be unnecessary if one used $\mathrm{T}$ scores. Indeed, in this example, the respondent's score would be $65 \mathrm{~T}$ and, thus, clinicians and researchers would immediately know that that person's score is 1.5 standard deviation above the normative sample.

In personality and psychological assessment, final scores of many instruments are expressed in $\mathrm{T}$ scores, to take advantage of the easiness of their interpretation. For example, the Minnesota Multiphasic Personality Inventory-2 (MMPI-2; Butcher et al., 2001) uses T scores to evaluate whether symptoms or problems are experienced as average adults do. In interpreting scale scores, scores of $65 \mathrm{~T}$ or above for most of the scales indicate that the way the test-taker experiences symptoms or problems is clinically significant. Other personality tests, for example the Personality Assessment Inventory (PAI; Morey, 1991, 2007), use a cut-off of 70T for interpreting the Clinical Scales. Generally, scores between 65T and 70T should draw the attention of clinicians and researchers on symptoms and problems experienced by the test-taker, whereas scores of 70T or above should indicate that the examinee experiences problems and symptoms in a way that diverges from the experience of average adults. According to these benchmarks, DERS scores between 65T and 70T may indicate the presence of problems in ER, whereas DERS scores of 70T or above may be considered as indicative of significant problems in ER. 
Developing Reference Values for the DERS

In terms of future directions, we would like to bring the reader's attention to a number of limitations characterizing our study. First, because we used archival data, we did not implement data recruitment procedures aimed at stratifying data collection to represent all Italian individuals with their different ages, genders, education levels, races, etc. However, that was not the goal of our work, as our primary intent was rather to develop a method to generate age and gender adjusted, normative reference values for the DERS. Given the encouraging results of our Bayesian analyses reported in Table 5, we believe that this goal has been achieved. Furthermore, it should be noted that even though our normative reference values are far from being representative of the entire Italian population, at the moment they still are the only available data in the literature, and therefore they still represent the best available solution at this time. A second limitation to keep in mind when reading this article is that the majority of the data we used came from student samples. As such, future studies with non-student samples are needed to test the generalizability of our method to other populations. Moreover, the oldest individual included in our research was 64 years old. Thus, future studies with older participants might reveal that the relationship of age to DERS scores is in fact curvilinear. Indeed, as it is the case for many cognitive skills, it is possible that ER would increase with age from adolescence to adulthood, but then would decrease from late adulthood to senescence. Hopefully, future research will explore this possibility. 
Developing Reference Values for the DERS

\section{Compliance with Ethical Standards}

\section{Conflict of Interest}

The authors declare that they have no conflict of interest.

\section{Experiment Participants}

The current study used archival data retrieved from three previously published research studies. In all cases, the research projects had been approved by the relevant institutional review boards.

\section{Informed Consent}

Informed consent was obtained from all individual participants included in the study. 
Developing Reference Values for the DERS

\section{References}

Altman, D. G., \& Bland, J. M. (1995). Absence of evidence is not evidence of absence.

British Medical Journal, 311(7003), 485. doi:10.1136/bmj.328.7438.476

Baer, R. A., Smith, G. T., Hopkins, J., Krietemeyer, J., \& Toney, L. (2006). Using selfreport assessment methods to explore facets of mindfulness. Assessment, 13(1), 27-45. doi:10.1177/1073191105283504

Blumberg, F. M., Giromini, L., \& Jacobson, L. B. (2016). Impact of Police Academy Training on Recruits' Integrity. Police Quarterly, 19(1), 63-86. doi:10.1177/1098611115608322

Buhrmester, D., Furman, W., Wittenberg, M. T., \& Reis, H. T. (1988). Five domains of Interpersonal Competence in peer relationships. Journal of Personality and Social Psychology, 55(6), 991-1008. doi:10.1037/0022-3514.55.6.991

Butcher, J. N., Graham, J.R., Ben-Porath, Y. S., Tellegen, A., Dahlstrom, W. G., \& Kaemmer, B. (2001). The Minnesota Multiphasic Personality Inventory-2 (MMPI-2): Manual for administration and scoring (Rev. ed.). Minneapolis: University of Minnesota Press.

Campbell-Sills, L., \& Barlow, D. H. (2007). Incorporating emotion regulation into conceptualizations and treatments of anxiety and mood disorders. In J. J. Gross (Ed.), Handbook of Emotion Regulation (pp. 542-559). New York: Guilford Press.

Cho, Y., \& Hong, S. (2013). The New Factor Structure of the Korean Version of the Difficulties in Emotion Regulation Scale (K-DERS) Incorporating Method Factor. Measurement and Evaluation in Counseling and Development, 46(3), 192-201. doi:10.1177/0748175613484033 
Developing Reference Values for the DERS

Cole, P. M., Michel, M. K., \& Teti, L. O. (1994). The development of emotion regulation and dysregulation: A clinical perspective. Monographs of the Society for Research in Child Development, 59(2-3), 73-102. doi:10.1111/j.1540-5834.1994.tb01278.x

Coutinho, J., Ribeiro, E., Ferreirinha, R., \& Dias, P. (2010). The Portuguese version of the Difficulties in Emotion Regulation Scale and its relationship with psychopathological symptoms. Revista de Psiquiatria clinica, 37(4), 145-51. doi:10.1590/S010160832010000400001

Dan-Glauser, E. S., \& Scherer, K. R. (2015). The Difficulties in Emotion Regulation Scale (DERS): Factor structure and consistency of a French translation. Swiss Journal of Psychology, 72(1), 5-11. doi:10.1024/1421-0185/a000093

de Campora, G., Giromini, L., Larciprete, G., Li Volsi, V., \& Zavattini, G. C. (2014). The impact of maternal overweight and emotion regulation on early eating behaviors. Eating Behaviors, 15(3), 403-409. doi:10.1016/j.eatbeh.2014.04.013

de Campora, G., Larciprete, G., Delogu, A. M., Meldolesi, C., \& Giromini, L. (2015). A longitudinal study on emotional dysregulation and obesity risk: From pregnancy to 3 years of age of the baby. Appetite, 96, 95-101. doi:10.1016/j.appet.2015.09.012

Fox, H. C., Axelrod, S. R., Paliwal P., Sleeper, J., \& Sinha, R. (2007). Difficulties in emotion regulation and impulse control during cocaine abstinence. Drug and Alcohol Dependence, 89(2-3), 298-301. doi:10.1016/j.drugalcdep.2006.12.026

Fox, H. C., Hong, K. A., \& Sinha, R. (2008). Difficulties in emotion regulation and impulse control in recently abstinent alcoholic compared with social drinkers. Addictive Behavior, 33(2), 388-394. doi:10.1016/j.addbeh.2007.10.002 
Developing Reference Values for the DERS

Giovannini, C., Giromini, L., Bonalume, L., Tagini, A., Lang, M., \& Amadei, G. (2014).

The Italian Five Facet Mindfulness Questionnaire: A contribution to its validity and reliability. Journal of Psychopathology and Behavioral Assessment, 36(3), 415-423. doi:10.1007/s10862013-9403-0

Giromini, L., Velotti, P., de Campora, G., Bonalume L., \& Zavattini, G. C. (2012). Cultural adaptation of the Difficulties in Emotion Regulation Scale: Reliability and validity of an Italian version. Journal of clinical psychology, 68(9), 989-1007. doi:10.1002/jclp.21876

Giromini, L., Viglione, D. J., \& McCullaugh, J. (2015). Introducing a Bayesian approach to determining degree of fit with existing Rorschach norms. Journal of Personality Assessment, 97(4), 354-363. doi:10.1080/00223891.2014.959127

Giromini, L., Brusadelli, E., Di Noto, B., Grasso, R., \& Lang, M. (2015). Measuring psychological mindedness: Validity, reliability, and relationship with psychopathology of an Italian version of the Balanced Index of Psychological Mindedness. Psychoanalytic Psychotherapy, 29(1), 70-87. doi:10.1080/02668734.2015.1006666

Giromini, L., de Campora, G., Brusadelli, E., D’Onofrio, E., Zennaro, A., Zavattini, G. C., \& Lang, M. (2015). Validity and reliability of the Interpersonal Competence Questionnaire: Empirical evidence from an Italian study. Journal of Psychopathology and Behavioral Assessment, 38(1), 113-123. doi:10.1007/s10862-015-9499-5

Glenn, C. R., \& Klonsky, E. D. (2009). Emotion dysregulation as a core feature of borderline personality disorder. Journal of Personality Disorders, 23(1), 20-28. doi:10.1521/pedi.2009.23.1.20

Gratz, K. L., \& Roemer, L. (2004). Multidimensional assessment of emotion regulation and dysregulation: Development, factor structure, and initial validation of the Difficulties in 
Developing Reference Values for the DERS

Emotion Regulation Scale. Journal of Psychopathology and Behavioral Assessment, 26(1), 41-

54. doi:10.1023/B:JOBA.0000007455.08539.94

Gratz, K. L., Bornovalova, M., A., Delany-Brumsey, A., Nick, B., \& Lejuez, C. W. (2007). A laboratory-based study of the relationship between childhood abuse and experiential avoidance among inner-city substance users: The role of emotional nonacceptance. Behavior Therapy, 38(3), 256-268. doi:10.1016/j.beth.2006.08.006

Gross, J. J. (1998). Antecedent- and response-focused emotion regulation: Divergent consequences for experience, expression, and physiology. Journal of Personality and Social Psychology, 74(1), 224-237. doi:10.1037/0022-3514.74.1.224

Gross, J. J., \& Muñoz, R. F. (1995). Emotion regulation and mental health. Clinical Psychology: Science \& Practice, 2(2), 151-164. doi:10.1111/j.1468-2850.1995.tb00036.x

Hervás, G., \& Jòdar, R. (2008). The Spanish version of the Difficulties in Emotion Regulation Scale. Clinica y Salud, 19(2), 139-156. Retrieved from http://scielo.isciii.es/pdf/clinsa/v19n2/v19n2a01.pdf

Jeffreys, H. (1961). Theory of Probability (3rd ed.). Oxford: Oxford University Press.

Klonsky, E. D. (2009). The functions of self-injury in young adults who cut themselves: Clarifying the evidence for affect regulation. Psychiatry Research, 166(2-3), 260-268. doi:10.1016/j.psychres.2008.02.008

Koole, S. L. (2009). The psychology of emotion regulation: An integrative review. Cognition \& Emotion, 23(1), pp. 4-41. doi:10.1080/02699930802619031

Linehan, M. M. (1993). Cognitive-behavioral treatment of borderline personality disorder. New York: The Guilford Press. 
Developing Reference Values for the DERS

McLaughlin, K. A., Mennin, D. S., \& Farach, F. J. (2007). The contributory role of worry in emotion generation and dysregulation in generalized anxiety disorder. Behaviour Research and Therapy, 45(8), 1735-1752. doi:10.1016/j.brat.2006.12.004

Mennin, D. S., Heimberg, R. G., Turk C. L., \& Fresco, D. M. (2005). Preliminary evidence for an emotion dysregulation model of generalized anxiety disorder. Behaviour Research and Therapy, 43(10), 1281-1310. doi:10.1016/j.brat.2004.08.008

Meyer, G. J., Viglione, D. J., Mihura, J. L., Erard, R. E., \& Erdberg, P. (2011). Rorschach Performance Assessment System. Administration, coding, interpretation, and technical manual. Toledo, OH: Rorschach Performance.

Miguel, F. K., Giromini, L., Colombarolli, M. S., Zuanazzi, A. C., \& Zennaro, A. (2016). A Brazilian investigation of the 36- and 16-item Difficulties in Emotion Regulation Scales. Journal of Clinical Psychology, in press. doi:10.1002/jclp.22404

Mitsopoulou, E., Kafetsios, K., Karademas, E., Papastefanakis, E., \& Simos, P. (2013). The Greek version of the Difficulties in Emotion Regulation Scale: Testing the factor structure, reliability and validity in an adult community Sample. Journal of Psychopathology and Behavioral Assessment, 35(1), 123-131. doi:10.1007/s10862-012-9321-6

Morey, L. C. (1991). Personality Assessment Inventory. Professional Manual. Odessa, FL: Psychological Assessment Resources.

Morey, L. C. (2007). Personality Assessment Inventory (PAI). Professional Manual (2nd ed.). Odessa, FL: Psychological Assessment Resources.

Nolen-Hoeksema, S., Wisco, B. E., \& Lyubomirsky, S. (2008). Rethinking rumination. Perspectives on Psychological Science, 3(5), 400-424. doi:10.1111/j.1745-6924.2008.00088.x 
Developing Reference Values for the DERS

Nyklíček, I., \& Denollet, J. (2009). Development and evaluation of the Balanced Index of Psychological Mindedness (BIPM). Psychological Assessment, 21(1), 32-44. doi: $10.1037 / \mathrm{a} 0014418$

Orgeta, V. (2009). Specificity of age differences in emotion regulation. Aging \& Mental Health, 13(6), 818-826. doi:10.1080/13607860902989661

Reese, J. B., Viglione, D. J., \& Giromini, L. (2014). A comparison between comprehensive system and an early version of the Rorschach Performance Assessment System administration with outpatient children and adolescents. Journal of Personality Assessment, 96(5), 515-522. doi:10.1080/00223891.2014.889700

Rouder, J. N., Speckman, P. L., Sun, D., Morey, R. D., \& Iverson, G. (2009). Bayesian t tests for accepting and rejecting the null hypothesis. Psychonomic Bulletin \& Review, 16(2), 225237. doi:10.3758/PBR.16.2.225

Rouder, J. N., \& Morey, R. D. (2011). A Bayes factor meta-analysis of Bem's ESP claim. Psychonomic Bulletin \& Review, 18(4), 682-689. doi:10.3758/s13423-011-0088-7

Ruganc1, R. N., \& Gençöz, T. (2010). Psychometric properties of a Turkish version of the Difficulties in Emotion Regulation Scale. Journal of Clinical Psychology, 66(4), 442-455. doi:10.1002/jclp.20665

Sarıtaş-Atalar, D., Gençöz, T., \& Özen, A. (2015). Confirmatory factor analyses of the Difficulties in Emotion Regulation Scale (DERS) in a Turkish adolescent sample. European Journal of Psychological Assessment, 31(1), 12-19. doi:10.1027/1015-5759/a000199

Sim, L., \& Zeman, J. (2005). Emotion regulation factors as mediators of bulimic symptoms in early adolescent girls. Journal of Early Adolescence, 25(4), 478-496. doi:10.1177/0272431605279838 
Developing Reference Values for the DERS

Sim, L., \& Zeman, J. (2006). The contribution of emotion regulation to body dissatisfaction and disordered eating in early adolescent girls. Journal of Youth and Adolescence, 35(2), 207-216. doi:10.1007/s10964-005-9003-8

Thompson, R. A. (1994). Emotion regulation: A theme in search of definition. Monographs for the Society for Research in Child Development, 59(2-3), 25-52. doi:10.1111/j.1540-5834.1994.tb01276.x

Tull, M. T., Barrett, H. M., McMillan, E. S., \& Roemer, L. (2007). A preliminary investigation of the relationship between emotion regulation difficulties and posttraumatic stress symptoms. Behavior Therapy, 38(3), 303-313. doi:10.1016/j.beth.2006.10.001

Urry, H. L., \& Gross, J. J. (2010). Emotion Regulation in Older Age. Current Directions in Psychological Science, 19(6), 352-357. doi:10.1177/0963721410388395

Wagenmakers, E. (2007). A practical solution to the pervasive problems of $p$ values. Psychonomic Bulletin \& Review, 14(5), 779-804. doi:10.3758/BF03194105

Wells, A., \& Papageorgiou, C. (1998). Social phobia: Effects of external attention on anxiety, negative beliefs, and perspective taking. Behavior Therapy, 29(3), 357-370. doi:10.1016/S0005-7894(98)80037-3

Whiteside, U., Chen, E., Neighbors, C., Hunter, D., Lo, T., \& Larimer, M. (2006). Difficulties regulating emotions: Do binge eaters have fewer strategies to modulate and tolerate negative affect? Eating behaviors, 8(2), 162-169. doi:10.1016/j.eatbeh.2006.04.001

Zlotnick, C., Donaldson, D., Spirito, A., \& Pearlstein, T. (1997). Affect regulation and suicide attempts in adolescent inpatients. Journal of the American Academy of Child and Adolescent Psychiatry, 36(6), 793-798. doi:10.1097/00004583-199706000-00016 
Developing Reference Values for the DERS

Table 1. Demographic Composition of the Sample.

\begin{tabular}{|c|c|c|c|c|}
\hline & \multicolumn{4}{|c|}{ Age } \\
\hline & Min & $\operatorname{Max}$ & Mean & SD \\
\hline \multicolumn{5}{|l|}{ Students } \\
\hline $\operatorname{Men}(n=265)$ & 18 & 57 & 23.0 & 6.0 \\
\hline Women $(n=724)$ & 18 & 64 & 23.3 & 6.1 \\
\hline Total $(n=989)$ & 18 & 64 & 23.2 & 6.1 \\
\hline \multicolumn{5}{|l|}{ Non Students } \\
\hline $\operatorname{Men}(n=92)$ & 30 & 63 & 43.5 & 9.3 \\
\hline Women $(n=131)$ & 29 & 61 & 42.0 & 8.8 \\
\hline Total $(n=223)$ & 29 & 63 & 42.6 & 9.0 \\
\hline \multicolumn{5}{|l|}{ Entire Sample } \\
\hline $\operatorname{Men}(n=357)$ & 18 & 63 & 28.3 & 11.4 \\
\hline Women $(n=855)$ & 18 & 64 & 26.1 & 9.4 \\
\hline Total $(n=1,212)$ & 18 & 64 & 26.8 & 10.1 \\
\hline
\end{tabular}


Developing Reference Values for the DERS

Table 2. Cronbach's Alphas $(N=1,212)$

\begin{tabular}{lcc}
\hline & No. of items & Alpha \\
\hline Nonacceptance & 6 & .84 \\
Goals & 5 & .85 \\
Impulse & 6 & .85 \\
Awareness & 6 & .76 \\
Strategies & 8 & .88 \\
Clarity & 5 & .84 \\
Total & 30 & .94 \\
\hline
\end{tabular}


Developing Reference Values for the DERS

Table 3. Developing Age and Gender Adjusted Scores: Multiple Regression Models

\begin{tabular}{|c|c|c|c|c|c|c|c|}
\hline & $F(2,805)$ & $p$ & $R^{2}$ & $\operatorname{Adj} . R^{2}$ & Raw $b$ & Standardized $\beta$ & $P$ \\
\hline Nonacceptance & 6.58 & .001 & .02 & .01 & & & \\
\hline (Constant) & & & & & 14.528 & - & $<.001$ \\
\hline Age & & & & & -.060 & -.127 & $<.001$ \\
\hline Gender & & & & & -.100 & -.010 & .787 \\
\hline Goals & 22.66 & $<.001$ & .05 & .05 & & & \\
\hline (Constant) & & & & & 16.448 & - & $<.001$ \\
\hline Age & & & & & -.096 & -.226 & $<.001$ \\
\hline Gender & & & & & .293 & .031 & .371 \\
\hline Impulse & 7.37 & .001 & .02 & .02 & & & \\
\hline (Constant) & & & & & 13.506 & - & $<.001$ \\
\hline Age & & & & & -.057 & -.126 & $<.001$ \\
\hline Gender & & & & & .351 & .035 & .326 \\
\hline Awareness & 5.55 & .004 & .01 & .01 & & & \\
\hline (Constant) & & & & & 14.312 & - & $<.001$ \\
\hline Age & & & & & .037 & .094 & .008 \\
\hline Gender & & & & & -.541 & -.060 & .086 \\
\hline Strategies & 9.71 & $<.001$ & .02 & .02 & & & \\
\hline (Constant) & & & & & 19.307 & - & $<.001$ \\
\hline Age & & & & & -.095 & -.151 & $<.001$ \\
\hline Gender & & & & & .213 & .015 & .666 \\
\hline Clarity & 11.53 & $<.001$ & .03 & .03 & & & \\
\hline (Constant) & & & & & 12.386 & - & $<.001$ \\
\hline Age & & & & & -.063 & -.168 & $<.001$ \\
\hline Gender & & & & & -.113 & -.013 & .700 \\
\hline Total & 11.88 & $<.001$ & .03 & .03 & & & \\
\hline (Constant) & & & & & 90.486 & - & $<.001$ \\
\hline Age & & & & & -.333 & -.169 & $<.001$ \\
\hline Gender & & & & & .102 & .002 & .947 \\
\hline
\end{tabular}


Developing Reference Values for the DERS

Table 4. Raw Age and Gender Adjusted DERS Scores: Descriptive Statistics within the

Developmental Sample $(n=808)$

\begin{tabular}{lcc}
\hline & $M$ & $S D$ \\
\hline Nonacceptance & 12.85 & 4.76 \\
Goals & 14.10 & 4.21 \\
Impulse & 12.22 & 4.59 \\
Awareness & 14.94 & 4.05 \\
Strategies & 16.92 & 6.32 \\
Clarity & 10.63 & 3.77 \\
Total & 81.64 & 19.80
\end{tabular}


Developing Reference Values for the DERS

Table 5. Age and Gender Adjusted DERS T-Scores: Testing the Null Hypothesis that T = 50

within the Validation Sample $(n=404)$

\begin{tabular}{lccccc}
\hline & $M$ & $S D$ & $t(403)$ & $p$ & $J Z S B$ \\
\hline Nonacceptance & 49.74 & 9.86 & -.53 & .60 & 21.95 \\
Goals & 50.51 & 10.11 & 1.01 & .31 & 15.19 \\
Impulse & 50.58 & 9.42 & 1.25 & .21 & 11.60 \\
Awareness & 50.47 & 10.30 & .91 & .36 & 16.72 \\
Strategies & 49.98 & 9.46 & -.05 & .96 & 25.22 \\
Clarity & 50.28 & 9.44 & .60 & .55 & 21.10 \\
Total & 50.32 & 9.38 & .69 & .49 & 19.92
\end{tabular}


Developing Reference Values for the DERS

Table 6. Correlation of Raw and Adjusted T Scores to Age and Gender, within the Validation

Sample $(n=404)$

\begin{tabular}{lcccc}
\hline & \multicolumn{2}{c}{ Raw Scores } & \multicolumn{2}{c}{ Adj. T Scores } \\
& Age & Gender & Age & Gender \\
\hline Nonacceptance & -.09 & -.07 & .04 & -.07 \\
Goals & $-.30 * *$ & $.14 * *$ & -.09 & .09 \\
Impulse & $-.19 * *$ & .02 & -.07 & -.03 \\
Awareness & .00 & -.08 & -.09 & -.02 \\
Strategies & $-.23 * *$ & .06 & -.08 & .04 \\
Clarity & $-.19 * *$ & .02 & -.02 & .02 \\
Total & $-.25 * *$ & .03 & -.08 & .01 \\
\hline Notes. Gender coded as dummy variable, with $\mathrm{M}=0$ and F & & & \\
\hline
\end{tabular}


Appendix A: Equations to Calculate Age and Gender Adjusted T-Scores from Raw DERS Values

$\begin{aligned} \text { Nonacceptance Adj.T Score } & =\frac{\text { Raw Nonacceptance Value }-(14.528-(\text { Age } \times .060)-(\text { Gender } \times .100))}{4.756} \times 10+50 \\ \text { Goals Adj.T Score } & =\frac{\text { Raw Goals Value }-(16.448-(\text { Age } \times .096)+(\text { Gender } \times .293))}{4.207} \times 10+50 \\ \text { Impulse Adj.T Score } & =\frac{\text { Raw Impulse Value }-(13.506-(\text { Age } \times .057)+(\text { Gender } \times .351))}{4.588} \times 10+50 \\ \text { Awareness Adj.T Score } & =\frac{\text { Raw Awareness Value }-(14.312-(\text { Age } \times .037)-(\text { Gender } \times .541))}{4.049} \times 10+50 \\ \text { Strategies Adj.T Score } & =\frac{\text { Raw Strategies Value }-(19.307-(\text { Age } \times .095)+(\text { Gender } \times .213))}{6.323} \times 10+50 \\ \text { Clarity Adj.T Score } & =\frac{\text { Raw Clarity Value }-(12.386-(\text { Age } \times .063)-(\text { Gender } \times .113))}{3.765} \times 10+50 \\ \text { Total Adj.T Score } & =\frac{\text { Raw Total Value }-(90.486-(\text { Age } \times .333)+(\text { Gender } \times .102))}{19.798} \times 10+50\end{aligned}$

Notes. Age: No. of years; Gender: $\mathrm{M}=0, \mathrm{~F}=1$. 